\title{
Pengaruh Kepuasan Kerja Terhadap Kinerja Karyawan PT. Pasifik Satelit Nusantara Jakarta
}

\author{
Dra.Eros Rosmiati,MM, Maya Sova,SE,M.Ak., Rahardian Hendra Prayoga,SE \\ Universitas Respati Indonesia \\ Email:eros.rosmiati@urindo.ac.id
}

\begin{abstract}
ABSTRAK
Tujuan penelitian ini untuk membahas tentang pengaruh kepuasan terhadap kinerja karyawan pada PT. Pasifik Satelit Nusantara Jakarta. Metode analisis data yang digunakan adalah Uji Validitas, Uji Reliabilitas, Uji Asumsi Klasik, dan Uji Hipotesis dengan uji $t$, uji $f$ dan determinasi ( $r$ 2). Jumlah sampel dalam penelitian ini adalah 80 karyawan PT. Pasifik Satelit Nusantara Jakarta.Berdasarkan hasil penelitian yang dapat dijelaskan tentang kepuasan kerja dengan $F^{\text {hitung }}(182,731)>F^{\text {tabel }} 3,960$ dengan taraf signifikansi di bawah 0,05, untuk kepuasan kerja diperoleh nilai sig 0,182<1,99, jadi kepuasan kerja berpengaruh terhadap kinerja karyawan.
\end{abstract}

Kata kunci : kepuasan kerja, kinerja, karyawan.

\section{ABSTRACT}

The Purpose of this study discusses the work satisfied on employee performance at PT. Pasifik Satelit Nusantara Jakarta. Data analysis methods used are Validity Test, Reliability Test, Classical Assumption Test, and Hypothesis Test with $t$ test, $f$ test and determination ( $r$ 2). The number of samples in this study were 80 employees of PT. Pasifik Satelit Nusantara Jakarta. Based on the results of research that can be explained about work satisfied with $F$ count $(182,731)>F$ table 3,960 with a significance level below 0.05 . In addition, for work satisfield obtained sig value $0.182<0.05$, significant work satisfied on employee performance.

\section{Keywords: Stress Work, Work Satisfied, Employee Performance}

\section{PENDAHULUAN}

Manajemen sebuah perusahaan atau organisasi dituntut untuk mengembangkan cara baru untuk mempertahankan pegawai pada produktivitas tinggi serta mengembangkan potensinya agar memberikan kontribusi maksimal pada organisasi. PT. Pasifik Satelit Nusantara Jakarta merupakan perusahaan yang bergerak di bidang pelayanan jaringan internet. Visi dan misi dari PT. Pasifik Satelit Nusantara Jakarta adalah menjadi jasa penyedia jaringan internet berstandar internasional dengan manajemen yang memberikan pelayanan dan produk terbaik dengan orientasi kepuasan pelanggan atau konsumen dan beroperasi dengan efisiensi yang inovatif dan teknologi yang mendukung. Dalam pencapaian visi dan misi tersebut maka diharapkan kinerja karyawan di PT. Pasifik Satelit Nusantara Jakarta dapat terus meningkat. Akan tetapi pada kenyataannya kinerja karyawan PT. Pasifik Satelit Nusantara Jakarta mengalami penurunan performa.

'Diantara faktor yang mempengaruhi penurunan kinerja adalah ketidak pusaan pegawai dibuktikan oleh kinerja karyawan yang tidak memenuhi target dan lambannya mengatasi keluhan dari pelanggan. Kepuasaan kerja menurut Edy Sutrisno (2014) menjadi masalah yang cukup menarik dan penting karena terbukti besar manfaatnya bagi kepentingan individu, industri dan masyarakat. Menurut Gilmer dalam Sutrisno, Edy (2014) bahwa faktor-faktor yang mempengaruhi kepuasan kerja adalah kesempatan untuk maju, kemauan kerja, gaji, perusahaan dan manajemen, pengawasan, faktor Instrinsik dan pekerjaan, kondisi kerja, aspek sosial dalam pekerjaan, komunikasin dan fasilitas. Fasilitas rumah sakit, cuti, dana pensiun atau perumahan merupakan standar suatu jabatan dan apabila dapat dipenuhi akan menimbulkan rasa puas. 
Sedangkan indikator yang menentukan kepuasan kerja (Robbins, 2015), yaitu pekerjaan yang secara mental menantang, kondisi kerja yang mendukung, gaji atau upah yang pantas dan kesesuaian kepribadian dengan pekerjaan.

Kinerja menurut Simanjuntak dalam Widodo (2015) adalah tingkatan pencapaian hasil atas pelaksanaan tugas tertentu. Simanjuntak juga mengartikan kinerja individu sebagai tingkat pencapaian atau hasil kerja seseorang dari sasaran yang harus dilaksanakan dalam kurun waktu tertentu. Didalam kinerja karyawan memiliki beberapa indikator, menurut Moeheriono (2014), adalah efektif, kualitas, ketepatan waktu dan keselamatan. Sedangkan faktor yang mempengaruhi kinerja seperti yang dikutip dari Gibson dalam Budianto dan Kartini (2015), adalah sebagai berikut faktor individu, faktor psikologis dan faktor organisasi.

Tujuan dari penelitian ini adalah untuk mengetahui pengaruh kepuasan kerja terhadap kinerja karyawan PT. Pasifik Satelit Nusantara Jakarta. Hasil dari penelitian ini diharapkan dapat sebagai bahan masukan bagi manajemen perusahaan. Dalam dunia akademis diharapkan hasil penelitian ini dapat menjadi bahan perbandingan bagi penelitian sejenis ataupun penelitian yang lebih luas.

\section{METODE}

Penelitian Penelitian ini dilakukan di PT. Pasifik Satelit Nusantara Jakarta yang berlokasi Jl.Gedung Kantor Taman A9, JL. DR. Ide Anak Gede Agung Lot 8, 9/A9 Kawasan Mega Kuningan, Jakarta 12950. Penelitian ini dilakukan April sampai dengan Juni 2019. Penelitian ini adalah penelitian asosiatif kausal dengan menggunakan pendekatan kuantitatif.

Populasi dalam penelitian adalah semua karyawan PT. Pasifik Satelit Nusantara Jakarta yang berjumlah 80 orang. Menurut Arikunto (2016) sampel adalah sebagian atau wakil populasi yang diteliti, untuk menentukan besarnya sampel apabila subyek kurang dari 100, lebih baik diambil semua, sehingga penelitiannya semua populasi. Yaitu semua karyawan PT. Pasifik Satelit Nusantara Jakarta yang berjumlah 80 orang menjadi subyek penelitian ini.

Sedangkan metode analisis datanya hubungan antar variabel menggunakan analisis regresi sederhana dengan uji $\mathrm{F}$ dan uji $\mathrm{t}$.

\section{HASIL}

1. Hasil Analisis Uji Instrumen

\section{a. Uji Validitas}

Dalam uji validitas menggunakan teknik korelasi Person Product Moment (Sugiyono, 2012).

Tabel 1

Hasil Uji Validitas Variabel Kepuasan Kerja (X)

\begin{tabular}{|l|c|c|c|}
\hline \multicolumn{1}{|c|}{ Item } & $\mathbf{r}^{\text {hitung }}$ & $\mathbf{r}^{\text {tabel }}$ & Keterangan \\
\hline Pernyataan 1 & 0.654 & 0,219 & Valid \\
\hline Pernyataan 2 & 0.693 & 0,219 & Valid \\
\hline Pernyataan 3 & 0.641 & 0,219 & Valid \\
\hline Pernyataan 4 & 0.737 & 0,219 & Valid \\
\hline Pernyataan 5 & 0.337 & 0,219 & Valid \\
\hline Pernyataan 6 & 0.428 & 0,219 & Valid \\
\hline Pernyataan 7 & 0.533 & 0,219 & Valid \\
\hline Pernyataan 8 & 0.576 & 0,219 & Valid \\
\hline Pernyataan 9 & 0.334 & 0,219 & Valid \\
\hline Pernyataan 10 & 0.377 & 0,219 & Valid \\
\hline
\end{tabular}

Sumber: Diolah dari hasil penelitian data primer, 2019

Dari Tabel 1 diatas dapat disimpulkan bahwa nilai validitas untuk masing-masing butir pernyataan variabel Kepuasan kerja $(\mathrm{X})$ memiliki nilai $r_{\text {hitung }}>r_{\text {tabel }}, \mathrm{n}-2 \quad(0,219)$. Sehingga dapat disimpulkan disimpulkan masing-masing item pernyataan yakni valid dan selanjutnya dapat digunakan dalam penelitian.

\section{Tabel 2}

Hasil Uji Validitas Variabel Kinerja Karyawan (Y)

\begin{tabular}{|l|c|c|c|}
\hline \multicolumn{1}{|c|}{ Variabel } & $\mathbf{r}^{\text {hitung }}$ & $\mathbf{r}^{\text {tabel }}$ & Keterangan \\
\hline Pernyataan 1 & 0.691 & 0,219 & Valid \\
\hline Pernyataan 2 & 0.763 & 0,219 & Valid \\
\hline Pernyataan 3 & 0.682 & 0,219 & Valid \\
\hline Pernyataan 4 & 0.773 & 0,219 & Valid \\
\hline Pernyataan 5 & 0.633 & 0,219 & Valid \\
\hline Pernyataan 6 & 0.404 & 0,219 & Valid \\
\hline Pernyataan 7 & 0.362 & 0,129 & Valid \\
\hline Pernyataan 8 & 0.490 & 0,219 & Valid \\
\hline Pernyataan 9 & 0.467 & 0,219 & Valid \\
\hline Pernyataan10 & 0.437 & 0,219 & Valid \\
\hline
\end{tabular}

Sumber: Diolah dari hasil penelitian data primer, 2019

Tabel 2 diatas dapat disimpulkan bahwa nilai validitas untuk masingmasing butir pernyataan variabel Kinerja Karyawan (Y) memiliki nilai $r_{\text {hitung }} \quad>r_{\text {tabel }}, n-2 \quad(0,219)$. Sehingga dapat disimpulkan masingmasing item pernyataan yakni valid dan selanjutnya dapat digunakan dalam penelitian. 


\section{b. Uji Reliabilitas}

Dalam uji realibilitas koefisien alpha atau cronbach's alpha Sugiyono (Sugiyono, 2015).

Tabel 3

Hasil Uji Reliabilitas

\begin{tabular}{|l|c|c|c|l|}
\hline Variabel & $\begin{array}{c}\text { Cronbach's } \\
\text { Alpha }\end{array}$ & $\begin{array}{c}\text { N of } \\
\text { Items }\end{array}$ & Alpha & Keterangan \\
\hline $\begin{array}{l}\text { Kepuasan } \\
\text { Kerja }\end{array}$ & 0,721 & 10 & 0,60 & Reliabel \\
\hline $\begin{array}{l}\text { Kinerja } \\
\text { Karyawan }\end{array}$ & 0,737 & 10 & 0,60 & Reliabel \\
\hline
\end{tabular}

Sumber: Diolah dari hasil penelitian data primer, 2019

Tabel 3 nilai cronbach's alpha pada variabel Kepuasan kerja (X) adalah 0,721 dan nilai cronbach's alpha pada variabel Kinerja Karyawan $(\mathrm{Y})$ adalah 0,737. Sehingga dapat disimpulkan bahwa variabel $X$ dan $Y$ reliabel.

\section{Uji Asumsi Klasik}

\section{a. Uji Normalitas}

Uji normalitas yang digunakan dalam pemelitian ini adalah dengan melihat berdasarkan uji kolmogorov smirnov, yaitu untuk melihat apakah suatu data dapat dikatakan norrmal atau tidak dengan asumsi apabila nilai signifikan yang dihasilkan > 0,05, maka data berdistribusi normal. Berikut hasil uji normalitas dengan uji kolmogorov smirnov:

Tabel 4

Hasil Uji Normalitas

One-Sample Kolmogorov-Smirnov Test

\begin{tabular}{|ll|r|r|}
\hline & & $\begin{array}{l}\text { kepuasan } \\
\text { kerja }\end{array}$ & $\begin{array}{l}\text { kinerja } \\
\text { karyawan }\end{array}$ \\
\hline $\mathrm{N}$ & 80 & 80 \\
Normal & Mean & 37.54 & 37.80 \\
Parameters & Std. Deviation & 3.930 & 4.268 \\
Most Extreme & Absolute & .123 & .094 \\
Differences & Positive & .103 & .078 \\
& Negative & -.123 & -.094 \\
Test Statistic & .123 & .094 \\
Asymp. Sig. (2-tailed) & $.005^{\mathrm{c}}$ & $.079^{\mathrm{c}}$ \\
\hline
\end{tabular}

diketahui:

Tabel 4 hasil uji normalitas,

a) Nilai signifikan variable kepuasan kerja adalah 0,005 $<0,05$. Maka dapat disimpulkan bahwa data diatas tidak berdistribusi normal.

b) Nilai signifikan variable kinerja karyawan adalah 0,079 >0,05. Maka dapat disimpulkan bahawa data diatas berdistribusi normal.

\section{b. Uji Multikolinearitas}

Kriteria pengujian multikolinearitas dilihat dari nilai VIF (Variance Inflation Factor) adalah

a) Jika nilai VIF > 10, maka dapat diartikan terjadi multikolinearitas terhadap data yang diuji.

b) Jika nilai VIF < 10, maka dapat diartikan tidak terjadi multikolinearitas terhadap data yang diuji.

Berikut adalah tabel uji multikolinearitas:

Tabel 5

Hasil Uji Multikolinearitas

\begin{tabular}{|c|c|c|}
\hline \multirow{2}{*}{ Model } & \multicolumn{2}{|c|}{ Colinearity Statistic } \\
\cline { 2 - 3 } & Tolerance & VIF \\
\hline kepuasan Kerja & 0,140 & 7,148 \\
\hline
\end{tabular}

Sumber: Diolah dari hasil penelitian data primer, 2019

Tabel 5 hasil uji multikolinearitas. Diketahui nilai tolerance variabel kepuasan kerja adalah $(0,140)>0,01$ dan nilai VIF variabel kepuasan kerja adalah $(7,148)<10,00$. Maka dapat disimpulkan bahwa data diatas tidak terjadi multikolinearitas.

\section{c. Uji Heteroskedastisitas}

Uji heteroskedastisitas bertujuan menguji apakah dalam model regresi terjadi ketidaksamaan variance dari residual satu pengamatan kepengamatan yang lain. Berikut adalah Hasil uji heteroskedastisitas

Table 6

Output analisis Glejser

Coefficients $^{a}$

\begin{tabular}{|l|r|r|r|r|r|}
\hline \multirow{2}{*}{ Model } & \multicolumn{2}{|c|}{$\begin{array}{c}\text { Unstandardized } \\
\text { Coefficients }\end{array}$} & $\begin{array}{c}\text { Standardized } \\
\text { Coefficients }\end{array}$ & & \multirow{2}{*}{} \\
\cline { 2 - 4 } & \multicolumn{1}{|c|}{$\mathrm{B}$} & Std. Error & Beta & \multicolumn{1}{c|}{$\mathrm{T}$} & Sig. \\
\hline 1 (Constant) & 1.042 & 1.527 & & .682 & .497 \\
$\mathrm{X}$ & -.064 & .101 & -.192 & -.633 & .528 \\
\hline
\end{tabular}

Dependent Variable: Abs_RES

Sumber: Diolah dari hasil penelitian data primer, 2019

Dari gambar 6, output glejser di atas diketahui bahwa :

Nilai sig untuk variable kepuasan kerja (X1) adalah 0,528 > 0,05 sehingga dapat disimpulkan bahwa model regresi diatas tidak terjadi gejala Heteroskedastisitas. 


\section{Uji Hipotesis}

a. Analisis Regresi Sederhana

Analisis regresi sederhana dalam penelitian ini dilakukan untuk mengetahui adanya hubungan antara variabel $x$ (Kepuasaan Kerja) dan variabel $Y$ (Kinerja Karyawan).

Tabel 7

Coefficients $^{\mathrm{a}}$

Hasil Uji Regresi Sederhana

\begin{tabular}{|c|c|c|c|c|c|}
\hline \multirow{2}{*}{ Model } & \multicolumn{2}{|c|}{$\begin{array}{l}\text { Unstandardized } \\
\text { Coefficients }\end{array}$} & \multirow{2}{*}{$\begin{array}{c}\begin{array}{c}\text { Standardized } \\
\text { Coefficients }\end{array} \\
\text { Beta }\end{array}$} & \multirow[b]{2}{*}{$\mathrm{T}$} & \multirow{2}{*}{ Sig. } \\
\hline & B & $\begin{array}{l}\text { Std. } \\
\text { Error }\end{array}$ & & & \\
\hline $\begin{array}{ll}1 & \text { (Constant) } \\
& \text { Kepuasan kerja }\end{array}$ & $\begin{array}{r}-1,692 \\
.186\end{array}$ & $\begin{array}{r}2.078 \\
.138\end{array}$ & -.171 & $\begin{array}{r}-815 \\
1,346\end{array}$ & $\begin{array}{l}.418 \\
.182\end{array}$ \\
\hline
\end{tabular}

Sumber: Diolah dari hasil penelitian data primer, 2019

Dari uji regresi sederhana diatas, dapat disusun persamaannya sebagai berikut: $Y=-1,692+0,186 X+e$

Dari tabel 7 diatas, hasil persamaan regresi sederhana dapat disimpulkan sebagai berikut:

a) konstanta sebesar -1,692 yang berarti jika variabel kepuasan kerja sama dengan nol, maka berpengaruh positif terhadap kinerja karyawan.

b) nilai koefisien regresi untuk variabel kepuasan kerja menunjukan nilai positif 0,186 artinya setiap kenaikan satu satuan variabel kepuasan kerja maka variabel kinerja karyawan akan naik sebesar $18,6 \%$.

\section{b. Koefisien Determinasi (Rsquare)}

Nilai koefisien determinasi (Rsquare) dipakai untuk memprediksi besar kontribusi pengaruh variabel kepuasan kerja $(X)$ terhadap variabel kinerja karyawan $(Y)$, besarnya nilai koefisien determinasi (Rsquare) berada antara 01. Berikut hasil uji koefisien determinasi ( $R$ square) yang dilakukan peneliti:

\section{Tabel 8}

Hasil Uji Determinasi (R square)

Model Summary ${ }^{\mathbf{b}}$
\begin{tabular}{|l|c|r|r|r|}
\hline Model & $\mathrm{R}$ & R Square & $\begin{array}{c}\text { Adjusted R } \\
\text { Square }\end{array}$ & $\begin{array}{r}\text { Std. Error of } \\
\text { the Estimate }\end{array}$ \\
\hline 1 & $.909^{\mathrm{a}}$ & .826 & .821 & 1.803 \\
\hline
\end{tabular}

a. Predictors: (Constant), $X$

b. Dependent Variable: $Y$

Tabel 8 diketahui nilai koefisien determinasi ( $R$ square) sebesar 0,821 berada diantara 0-1. Angka $\mathrm{R}$ square $(0,821)$ mengandung arti bahwa kepuasan kerja (X1) berpengaruh terhadap kinerja karyawan $(\mathrm{Y})$ sebesar $82,1 \%$ sedangkan sisanya $(100 \%$ $82,1 \%=17,9 \%$ ) dipengaruhi oleh variabel lain diluar model regresi ini.

\section{c. Uji Simultan (Uji F)}

Uji Simultan (uji F) ini digunakan untuk melihat apakah variabel independent Kepuasan Kerja (X) mempunyai pengaruh positif dan signifikan terhadap variabel dependent yaitu Kinerja Karyawan $(\mathrm{Y})$. berikut adalah tabel hasil uji simultan (uji F):

Tabel 9

Hasil Uji Simultan (Uji F)

ANOVA $^{\mathrm{a}}$

\begin{tabular}{|l|l|r|l|l|l|}
\hline Model & Sum of & Mean & & \\
\hline 1 Regression & \multicolumn{1}{|l|}{1188.411} & 2 & 594.205 & 182.731 & $.000^{\mathrm{b}}$ \\
Residual & 250.389 & 77 & 3.252 & & \\
Total & 1438.800 & 79 & & & \\
\hline
\end{tabular}

a. Dependent Variable: $Y$

b. Predictors: (Constant), $\mathrm{X}$

Tabel 9 diketahui bahwa nilai $F$ hitung sebesar 182,731 > F table sebesar 3,96 $(80-2=78,2-1=1)$, maka dapat ditarik kesimpulan bahwa variabel kepuasan Kerja $(X)$ berpengaruh terhadap variabel kinerja karyawan $(\mathrm{Y})$.

\section{d. Uji Parsial (Uji t)}

Uji parsial (uji t) dalam analisis regresi linear sederhana bertujuan untuk mengetahui apakah kepuasan kerja (X) berpengaruh signifikan terhadap kinerja karyawan $(\mathrm{Y})$. 
Tabel 10

Coefficients $^{a}$

\begin{tabular}{|c|c|c|c|c|c|}
\hline \multirow[b]{2}{*}{ Model } & \multicolumn{2}{|c|}{$\begin{array}{l}\text { Unstandardized } \\
\text { Coefficients }\end{array}$} & \multirow{2}{*}{ 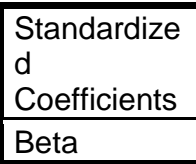 } & \multirow[b]{2}{*}{ t } & \multirow[b]{2}{*}{ Sig. } \\
\hline & $B$ & Std. Error & & & \\
\hline $\begin{array}{ll}1 & \text { (Constant) } \\
& \mathrm{X}\end{array}$ & $\begin{array}{r}-1.692 \\
.186\end{array}$ & $\begin{array}{r}2.078 \\
.138\end{array}$ & .171 & \begin{tabular}{|l|}
-.815 \\
1.346
\end{tabular} & $\begin{array}{l}.418 \\
.182\end{array}$ \\
\hline
\end{tabular}

a. Dependent Variable: $Y$

Tabel 10 diketahui nilai sig. variabel kepuasan kerja sebesar 0,182 <1,99 sehingga dapat disimpulkan bahwa variabel kepuasan kerja (X) berpengaruh signifikan terhadap kinerja karyawan $(\mathrm{Y})$.

\section{KESIMPULAN}

1. Kepuasan kerja $(\mathrm{X})$ berpengaruh terhadap kinerja karyawan, nilai $F$ hitung sebesar $182,731>\mathrm{F}$ table sebesar 3,96 $(80-2=78$, 2-1 = 1), maka dapat ditarik kesimpulan bahwa variabel kepuasan Kerja (X) berpengaruh terhadap variabel kinerja karyawan (Y) pada PT. Satelit Nusantara Jakarta.

2. Kepuasan kerja (X2) berpengaruh secara terhadap kinerja karyawan (Y) PT. Pasifik Satelit Nusantara Jakarta., terlihat pada uji t dimana nilai signifikan lebih besar yaitu $0,182<1,99$.

3. Dengan diketahuinya kepuasan kerja mempunyai pengaruh positif dan signifikan terhadap kinerja karyawan PT. Pasifik Satelit Nusantara Jakarta dapat dijadikan tambahan wawasan dan bahan pertimbangan manajemen PT. Pasifik Nusantara Jakarta untuk lebih meningkatkan dan mengevaluasi agar kinerja karyawan semakin optimal dipertahankan dengan baik, sehingga tujuan dari perusahaan dapat tercapai.

\section{DAFTAR PUSTAKA}

1. Aji tri Budianto dan Amelia Kartini. 2015,pengaruh Ingkungan kerja padakinerja karyawan pada $P T$. perusahaan gas Negara (PERSERO) tbk SBU distributor wilayah 1 Jakarta. Jurnal ilmiah manajemen universitas pamulang vol. 3, no. 1, Oktober 2015.

2. Arikunto, S. (2016). Prosedur Penelitian: Suatu Pendekatan Praktik. Jakarta: Rineka Cipta.

3. Edy Sutrisno, 2014. Manajemen Sumber Daya Manusia. Cetak Ke Enam. Pranada Media Group, Jakarta.

4. Moeheriono (2014) pengukuran kerja berbasis kompetensi. Edisi revisi.rajawalipers, Jakarta.

5. Stephen, Robbins (2015), Perilaku Organisasi, Penerbit Salemba Empat, Jakarta.

6. Sugiyono. 2012. Metode Penelitian Kuantitatif, Kualitatif, dan $R \& D$, Bandung: Alfabeta.

7. Sugiyono (2015). Metode Penelitian Kombinasi (Mix Methods). Bandung: Alfabeta.

8. Widodo, S. E. (2015). Manajemen Pengembangan Sumber Daya Manusia, Pustaka Belajar,Yogyakarta. 